\title{
Meta-analysis on the prevalence of REM sleep behavior disorder symptoms in Parkinson's disease
}

\author{
Jia Zhang, Chuan-Ying Xu and Jun Liu (iD
}

\begin{abstract}
Background: Our study was aimed to evaluate the risk of a selected non-motor symptom, namely rapid eye movement behavior disorder (RBD) symptoms, among patients with newly diagnosed Parkinson disease compared with health controls.

Methods: The Preferred Reporting Items for Systematic Reviews and Meta-Analyses (PRISMA) guidelines for meta-analysis and Cochrane manual were followed. Studies on RBD symptoms and PD were searched using PubMed, Embase, Web of Science and Cochrane library databases. All studies were published before August $3^{\text {rd }}, 2016$. Eligible studies were those that reported a prevalence of RBD symptoms among newly diagnosed PD and health control. Pooled odds ratios (ORs) with 95\% confidence intervals (Cls) were calculated by random-effected models. Heterogeneity across studies was assessed using Cochran Q and I² statistics.

Results: We identified eight studies including 2462 PD patients and 3818 health controls. The overall prevalence of RBD symptoms in PD was 582/2462 (23.6\%) compared to 131/3818 (3.4\%) in control. And the pooled OR was $5.69(95 \% \mathrm{Cl} 3$. 60 to 9.00; $p=0.001$ ) with a moderate heterogeneity $I^{2}=70.5 \%$. After excluding the study of low weight, the overall polled OR was 3.54 ( $95 \% \mathrm{Cl} 2.77$ to $4.52 ; p<0.00001)$ and the heterogeneity was completely eliminated $\left(I^{2}=0 \%\right)$.

Conclusions: RBD symptoms are common non-motor symptoms of PD, and people with PD are at a higher risk of developing RBD. Further studies are needed to understand the natural history of RBD symptoms in PD and its etiological and clinical implications.
\end{abstract}

Keywords: Parkinson's disease, RBD symptoms, Non-motor symptoms, Meta-analysis, Prevalence

\section{Background}

Parkinson's disease (PD) is the second most prevalent neurodegenerative disease with a prevalence of approximately $0.4 \%$ in people aged 65 and older, and it increases with age [1]. Apart from motor dysfunction, PD patients also suffer from a variety of non-motor symptoms (NMS), such as hyposmia, rapid eye movement sleep behavior disorder (RBD), constipation and depression [2]. However, certain non-motor symptoms might precede the development of motor symptoms by many years [3]. RBD is characterized by the loss of normal atonia of REM sleep, resulting in an apparent acting out of dream content [4].

\footnotetext{
* Correspondence: jly0520@hotmail.com

Department of Neurology \& Institute of Neurology, Ruijin Hospital affiliated to Shanghai Jiaotong University School of Medicine, Shanghai, People's Republic of China
}

It has been reported that RBD as a premotor feature occurred in $38 \%$ of patients who developed PD in a mean interval of 3.5 years after a RBD diagnosis [5]. The presence of RBD in prodromal PD is consistent with the Braak hypothesis which implies that it may occur as the result of underlying Lewy pathogenesis at lower brainstem before invading substantial nigra [6]. However, reported prevalence of RBD in PD patients varies greatly from 20 to $72 \%$ [7], and the prevalence of probable RBD was estimated to be about $4.9 \%$ in the general population [8]. To date, no meta-analysis has examined the magnitude of risk associated with PD and the development of RBD. We therefore conducted a meta-analysis to estimate the prevalence of RBD symptoms among patients with newly diagnosed PD compared with health controls. 


\section{Methods}

\section{Search strategy}

We conducted a systematic search of original published studies that reported the prevalence of RBD symptoms in PD and health controls. Two researchers (JZ and CYX) independently undertook a search on PubMed, Web of Science, Embase and Cochrane library databases for literature published in English, which were published before August $3^{\text {rd }}$, 2016. We combined medical subject heading (MeSH) terms including "PD, RBD" and text terms including "Idiopathic Parkinson's Disease, Lewy Body Parkinson Disease, Primary Parkinsonism, Parkinsonism, Primary Parkinson Disease, Paralysis Agitans" and "REM Behavior Disorder, Rapid Eye Movement Sleep Behavior Disorder" as our search strategy. Restrictions were made to observational epidemiologic studies involving humans. Titles and abstracts were screened for their suitability. Articles whose abstracts did not report on RBD symptoms and PD were excluded. Full articles were then obtained and reviewed to determine suitability for inclusion or exclusion. Differences of opinion between the researchers were resolved through discussion. The reference lists of all full articles were included. In addition, references from reviews that were identified in the original study, were hand-searched as additional articles, and then subjected to the same filtering process as described above.

\section{Inclusion criteria}

Published articles that met the following criteria were included: 1) observational studies with a cohort, case-control or cross-section design; 2) cases where patients were diagnosed with PD according to standard clinical criteria, such as UK Parkinson's Disease Society Brain Bank Criteria [9]; 3) controls were drawn from the same population as cases; 4) controls were healthy or had no history of neurological disease; 5) RBD symptoms in controls were assessed over the same time period as patients; 6) RBD symptoms were assessed by means of polysomnography (PSG), or structured questionnaire, or coded in patient medical records or medication used to treat RBD symptoms and 7) original data were reported.

\section{Exclusion criteria}

We excluded studies for the following reasons: 1) studies in the form of case report, review, conference abstracts, or letters that did not report new data; 2) studies that only provided risk estimates such as relative risk without numbers of individuals; 3) duplicate populations; 4) did not provide adequate details of the control group; 5) did not report sufficient data to calculate risk estimates; and 6) non-English publications or non-human studies.

\section{Data extraction}

Two researchers (JZ and CYX) reviewed all abstracts independently either to determine the eligibility criteria or for examining the appropriateness on the research issue. Data were compared and disagreements were resolved by a consensus. The following information was extracted from each study, and included: name of first author, year of publication, study data, study design, sample size, patient mean age, geographical region, RBD symptoms assessment method and other relevant study characteristics. Finally, studies were assessed for quality using the NewcastleOttawa Scale (NOS) [10].

\section{Statistical analysis}

Measures of effect were combined using standard metaanalysis methods. We used the odds ratio (OR) with a 95\% confidence interval (CI) as the metric of risk, using the random effects model. Heterogeneity across studies was evaluated by the Cochrane's Q statistic and by $\mathrm{I}^{2}$ test, the percentage of $\mathrm{I}^{2}$ around 25, 50 and 75\% mean low, medium and high heterogeneity [11]. A sensitivity analysis was conducted to evaluate the source of heterogeneity. Publication bias was assessed using the Egger test and a funnel plot [12]. Statistical analysis was undertaken in STATA (version 12.0; StataCorp, Corporation, College Station, TX, USA) and RevMan (version 5.1; the Cochrane Collaboration, Oxford, United Kingdom).

\section{Results}

The literature search yielded 749 records (include three studies from hand searching of references) after duplicates were removed. Of these, 673 records were excluded on the basis of their title and abstract. Review of the remaining 76 full articles led to 68 exclusions based on criteria described above. Finally, eight studies fulfilled our inclusion criteria and were included in our meta-analysis with a total number of 2462 PD patients and 3818 health controls (Fig. 1).

Of these, seven studies were case-control designs [14-20], and one was a cross-sectional study [21]. Most of the studies were conducted in Europe and North America [15, 16, 1821], with one conducted in Asia [14], and one study conducted in Africa [17]. We divided the eight studies into two subgroups according to different RBD assessment methods described in the articles. If RBD was diagnosed with ICD (International classification of disease), RBD-SQ (RBDscreening questionnaire) or PSG, the symptom was defined as definite $\operatorname{RBD}[14,16,21]$. If $\mathrm{RBD}$ was diagnosed with NMS-SQ, self-made Questionnaire or MSQ (Mayo Sleep Questionnaire), the symptom was defined as probable RBD $[15,17-20]$. Summary characteristics for all included studies are provided in (Table 1). With NOS quality criteria, all studies scored $\geq 7 / 9$ and six of the included studies scored 8/9.

The overall prevalence of RBD symptoms in PD was $582 / 2462(23.6 \%)$ compared to $131 / 3818$ (3.4\%) in control. And the pooled OR was 5.69 (95\% CI 3.60 to 9.01) with a moderate heterogeneity $\left(\mathrm{I}^{2}=70.6 \% ; p=\right.$ 0.001) (Fig. 2). Subgroup analysis according to different 


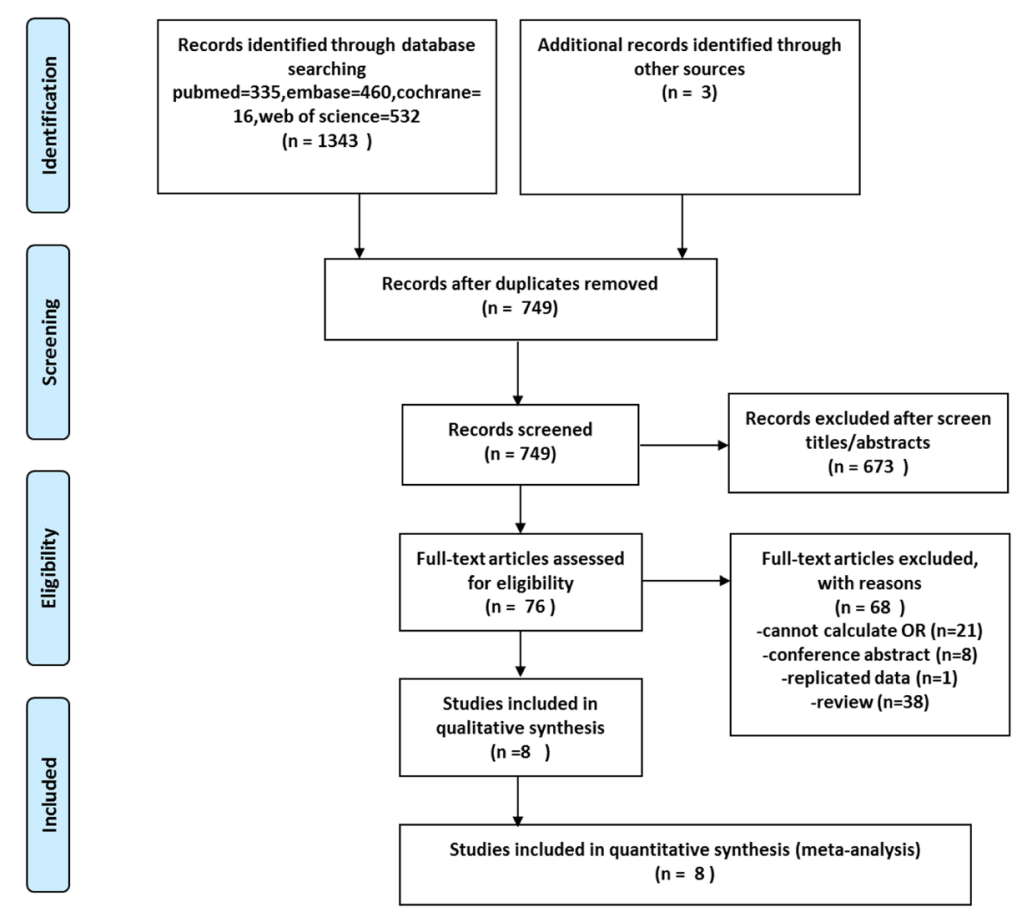

Fig. 1 PRISMA [13] flow chart of literature review and data abstraction

diagnostic methods showed that the pooled OR for "Probable RBD" group was 6.08 (95\% CI 3.87 to 11.93) with evidence of moderate heterogeneity $\left(\mathrm{I}^{2}=58.2 \% ; p=\right.$ 0.048 ) and 4.14 for "Definite RBD" (95\% CI 2.21 to 7.78 ) with medium heterogeneity $\left(\mathrm{I}^{2}=68.7 \% ; p=0.041\right)$. After excluding the study of low weight $[15,19,21]$, the overall polled OR was 3.54 (95\% CI 2.77 to 4.52 ) and the heterogeneity was completely eliminated $\left(\mathrm{I}^{2}=0 \% ; p<\right.$ $0.00001)$. Visual inspections of the funnel plot revealed a little asymmetry (Fig. 3) and significant publication bias

Table 1 Characteristics of studies included in the Meta-analysis

\begin{tabular}{|c|c|c|c|c|c|c|c|c|c|c|c|c|}
\hline Author & Year & $\begin{array}{l}\text { Study } \\
\text { design }\end{array}$ & Country & Population & $\begin{array}{l}\mathrm{PD} \\
\text { cases }\end{array}$ & $\begin{array}{l}\text { PD + RBD } \\
\text { Number }\end{array}$ & $\begin{array}{l}\text { Control } \\
\text { Number }\end{array}$ & $\begin{array}{l}\text { Con + RBD } \\
\text { Number }\end{array}$ & $\begin{array}{l}\text { RBD } \\
\text { assessment }\end{array}$ & $\begin{array}{l}\text { RBD } \\
\text { diagnosis }\end{array}$ & $\begin{array}{l}\text { RBD assessment } \\
\text { before or after } \\
\text { PD diagnosis }\end{array}$ & $\begin{array}{l}\text { NOS } \\
\text { score }\end{array}$ \\
\hline $\begin{array}{l}\text { Wu } \\
{[14]}\end{array}$ & 2015 & $\begin{array}{l}\text { case- } \\
\text { control }\end{array}$ & Taiwan & $\begin{array}{l}\text { Taiwan National } \\
\text { Health Insurance } \\
\text { Research Database }\end{array}$ & 705 & 30 & 2820 & 33 & ICD-9-CM & definite & before & 8 \\
\hline $\begin{array}{l}\text { Sunyer } \\
{[15]}\end{array}$ & 2015 & $\begin{array}{l}\text { case- } \\
\text { control }\end{array}$ & $\begin{array}{l}\text { Spanish } \\
\text { and } \\
\text { Austrian }\end{array}$ & outpatient clinics & 109 & 30 & 107 & 3 & NMS-SQ & probable & after & 8 \\
\hline $\begin{array}{l}\text { Baig } \\
{[16]}\end{array}$ & 2015 & $\begin{array}{l}\text { case- } \\
\text { control }\end{array}$ & UK & $\begin{array}{l}\text { Oxford Parkinson } \\
\text { Disease Center }\end{array}$ & 796 & 253 & 287 & 42 & RBD-SQ & definite & after & 8 \\
\hline $\begin{array}{l}\text { Trinh } \\
\text { [17] }\end{array}$ & 2014 & $\begin{array}{l}\text { case- } \\
\text { control }\end{array}$ & Tunisia & $\begin{array}{l}\text { Institut National } \\
\text { de Neurologie, } \\
\text { Tunis }\end{array}$ & 390 & 100 & 124 & 10 & Questionnaire & probable & after & 7 \\
\hline $\begin{array}{l}\text { Doring } \\
\text { [21] }\end{array}$ & 2014 & $\begin{array}{l}\text { cross- }^{-} \\
\text {section }\end{array}$ & Germany & $\begin{array}{l}\text { Paracelsus Elena } \\
\text { Klinik in Kassel }\end{array}$ & 158 & 40 & 110 & 2 & PSG & definite & after & 8 \\
\hline $\begin{array}{l}\text { Khoo } \\
{[18]}\end{array}$ & 2013 & $\begin{array}{l}\text { case- } \\
\text { control }\end{array}$ & UK & $\begin{array}{l}\text { Newcastle-upon-Tyne } \\
\text { and Gateshead }\end{array}$ & 159 & 55 & 99 & 8 & NMS-SQ & probable & after & 8 \\
\hline $\begin{array}{l}\text { Adler } \\
{[19]}\end{array}$ & 2011 & $\begin{array}{l}\text { case- } \\
\text { control }\end{array}$ & USA & $\begin{array}{l}\text { Banner Sun Health } \\
\text { Research Institute }\end{array}$ & 49 & 34 & 175 & 23 & MSQ & probable & after & 8 \\
\hline $\begin{array}{l}\text { Chaudhuri } \\
\text { [20] }\end{array}$ & 2006 & $\begin{array}{l}\text { case- } \\
\text { control }\end{array}$ & Multicenter & Multicenter & 123 & 40 & 96 & 10 & NMS-SQ & probable & after & 9 \\
\hline Total & & & & & 2462 & 582 (23.6\%) & 3818 & 131 (3.4\%) & & & & \\
\hline
\end{tabular}

PD Parkinson disease, RBD Rapid eye movement behavior disorder, ICD International classification of disease, NMS non-motor symptom, SQ screening questionnaire, MSQ Mayo Sleep Questionnaire, PSG polysomnography, NOS Newcastle-Ottawa Scale 


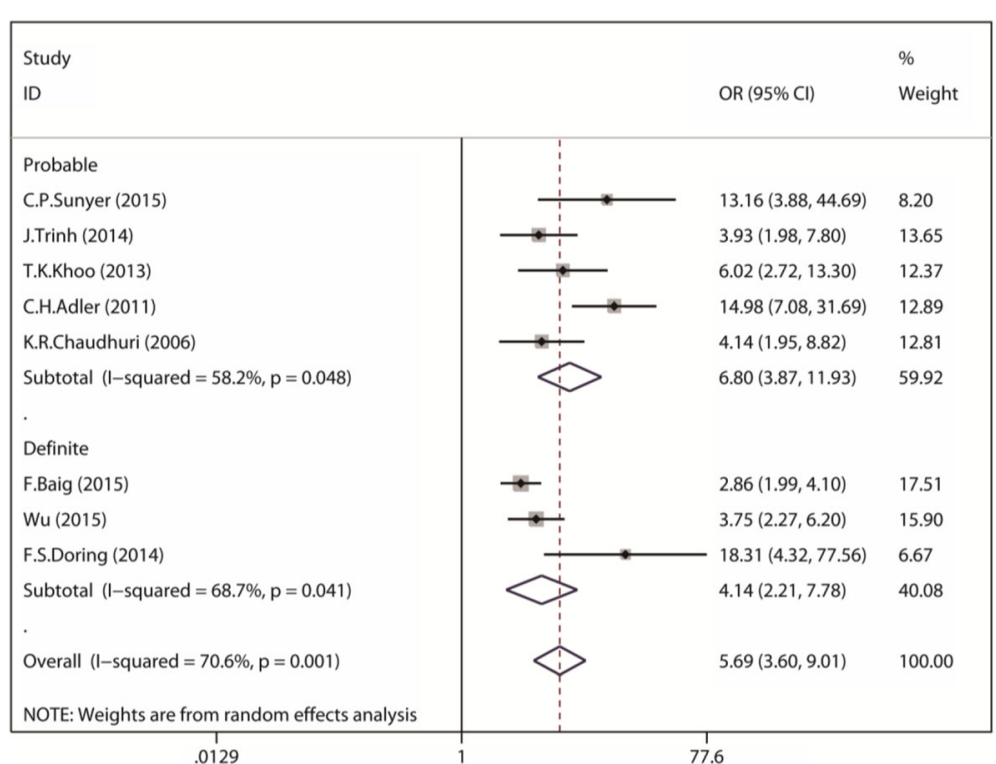

Fig. 2 Forest plot demonstrating increased RBD risk in those with PD as compared with those control (Cl, confidence interval; OR, odds ratio)

was detected from results of the statistical test (Begg test: $p=0.019$; Egger test: $p=0.011$ ).

The results of our meta-analysis show a definite association between PD and RBD symptoms. Since studies included were of different study design, population bases and methods of exposure ascertainment, the heterogeneity across the studies was high. To identify studies that may have contributed to the pooled heterogeneity, we removed each of the eight studies (one study at a time) and examined the magnitude and direction of the polled relative risk (RR) after the removal of each study. This approach was repeated until the $\mathrm{I}^{2}$ statistic was deemed zero. Three studies $[15,19,21]$ were identified as the source of heterogeneity in this study. After removing all of those studies, the polled OR was 3.54 (95\% CI 2.77 to $4.52 ; \mathrm{I}^{2}$ statistic $\left.=0 \%\right)$, and the

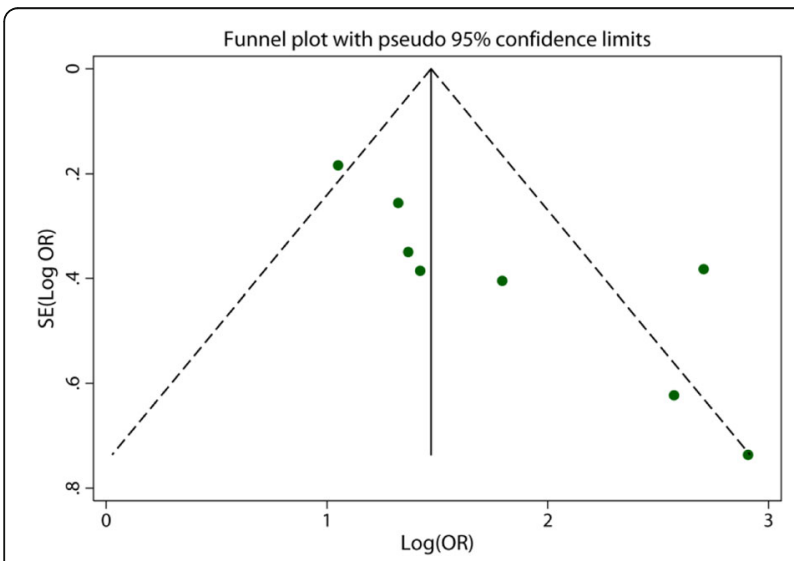

Fig. 3 Funnel plot assessing publication bias in the study of RBD association with PD association between PD and the risk of developing RBD symptoms was still statistically significant.

\section{Discussion}

Our systematic review and meta-analysis offers a confirmation of the association between PD and a subsequent diagnosis of RBD. The pooled prevalence of RBD symptoms in $\mathrm{PD}$ and control is 23.6 vs. $3.4 \%$, and the patients who had symptoms of PD carried a 3.60 to 9.00 -fold increased risk for developing RBD compared to health controls. It is important to quantify the magnitude of the association between PD and subsequent RBD symptoms, as this may underpin efforts to identify higher risk participants for entry to interventional studies with neuroprotective aims.

REM sleep behavior disorder (RBD) is a parasomnia disorder characterized by repeated episodes of dream enactment behavior and REM sleep without atonia (RSWA) during polysomnography (PSG) [22]. The main suspected mechanism of RBD is a lesion in the REM sleep atonia system, which is mainly located in the pontomedullary area [23]. RBD is important as a valuable preclinical marker of PD. Firstly, idiopathic RBD converted to neurodegenerative disease at a high rate ranging from 28 to $82 \%$ [24-27]. Secondly, many potential early marker of PD are significantly abnormal in iRBD, such as decreased striatal dopamine transporter binding, marked EEG slowing, substantial nigra hyperechogenicity and impaired olfaction [28-30]. Lastly, RBD is also associated with some specific PD phenotypes. It is known that age, gender, disease duration, motor disability, dopaminergic drug, motor phenotype, cognition, and autonomic dysfunction are different in PD patients with RBD compared to PD patients without the disorder [7]. 
Our study demonstrates that there is potential for publication bias based on the funnel plot and significant publication bias was detected from results of the statistical test (Begg test: $p=0.019$; Egger test: $p=0.011$ ). This might result in an overestimation of the association between PD and the risk of RBD symptoms. Considering that we only included eight studies which were assessed via means of the NOS, and all studies included in the main analysis had scores $\geq 7 / 9$, we can conclude that the risk estimate that resulted from this analysis may also be viewed as a fairly strict estimate, and a result of the pooling of data from only the highest quality studies.

Similar to any other meta-analysis of observational studies, our study is subject to several limitations. First, we limited our search to publications in English and therefore might have missed a small number of relevant publications. Second, recall bias may affect the quality of information retrieved from participants in case-control studies and the assessment of RBD symptoms may vary from one study to another. Third, more high quality and large sample sizes observation studies estimating the risk of RBD symptoms in PD should be included in order to avert the publication bias.

\section{Conclusion}

In conclusion, despite these limitations, we pooled data from 6280 people across eight studies to provide a consolidated risk that estimated relating PD to the development of RBD symptoms. Most of the evidence was of the highest quality and the conclusion was considered robust. Further prospective research is needed to examine the presence of RBD symptoms and its relationship to PD, in order to better understand the etiology and natural history of PD.

\section{Abbreviations \\ MSQ: Mayo sleep questionnaire; NMS: Non-motor symptoms; NOS: Newcastle-Ottawa Scale; OR: Odds ratio; PD: Parkinson's disease; PSG: Polysomnography; RBD: Rapid eye movement behavior disorder: RSWA: REM sleep without atonia}

\section{Acknowledgements}

We thank all the authors of the included studies, and especially thank Pei Huang and Dun-Hui Li for study coordination.

\section{Funding}

This work was supported by grants from National Natural Science Fund (81071024, 81171202, 81471287, 81371407 and 81228007), Shanghai Shuguang Program (11SG20), and Shanghai Municipal Education Commission—Gaofeng Clinical Medicine Grant Support (20152201).

\section{Availability of data and materials}

All data generated or analyzed during this study are included in this published article.

\section{Authors' contributions}

$J \mathrm{~L}$ designed the whole study and gave suggestions on revising the article. $\mathrm{JZ}$ and CYX searched and selected the studies, JZ and CYX analyzed the data, drafted and revised the article. JZ prepared figures. All authors read and approved the final manuscript.

\section{Competing interests}

The authors declare that they have no competing interest.
Consent for publication

Not applicable.

\section{Ethics approval and consent to participate}

The study was approval by the Institutional Ethics Committee of Shanghai Jiao Tong University School of Medicine ((2011) ethics committee No.13). Written consent form to use their clinical data was obtained from each participant.

Received: 19 September 2016 Accepted: 11 January 2017

Published online: 04 February 2017

\section{References}

1. Pringsheim T, Jette N, Frolkis A, Steeves TD. The prevalence of Parkinson's disease: a systematic review and meta-analysis. Mov Disord. 2014;29(13):1583-90.

2. Postuma RB, Berg D, Stern M, Poewe W, Olanow CW, Oertel W, Obeso J, Marek K, Litvan I, Lang AE, et al. MDS clinical diagnostic criteria for Parkinson's disease. Mov Disord. 2015;30(12):1591-601.

3. Postuma RB, Aarsland D, Barone P, Burn DJ, Hawkes CH, Oertel W, Ziemssen T. Identifying prodromal Parkinson's disease: pre-motor disorders in Parkinson's disease. Mov Disord. 2012;27(5):617-26.

4. Schenck CH, Bundlie SR, Ettinger MG, Mahowald MW. Chronic behavioral disorders of human REM sleep: a new category of parasomnia. Sleep. 1986; 9(2):293-308.

5. Schenck CH, Bundlie SR, Mahowald MW. Delayed emergence of a parkinsonian disorder in $38 \%$ of 29 older men initially diagnosed with idiopathic rapid eye movement sleep behaviour disorder. Neurology. 1996; 46(2):388-93.

6. Braak H, Del Tredici K, Rüb U, de Vos RA, Steur ENJ, Braak E. Staging of brain pathology related to sporadic Parkinson's disease. Neurobiol Aging. 2003; 24(2):197-211.

7. Kim YE, Jeon BS. Clinical implication of REM sleep behavior disorder in Parkinson's disease. J Parkinsons Dis. 2014;4(2):237-44.

8. Ma JF, Hou MM, Tang HD, Gao X, Liang L, Zhu LF, Zhou Y, Zha SY, Cui SS, Du JJ, et al. REM sleep behavior disorder was associated with Parkinson's disease: a community-based study. BMC Neurol. 2016;16:123.

9. Hughes AJ, Daniel SE, Kilford L, Lees AJ. Accuracy of clinical diagnosis of idiopathic Parkinson's disease: a clinico-pathological study of 100 cases. J Neurol Neurosurg Psychiatry. 1992;55(3):181-4.

10. GA Wells BS, O'Connell D, Peterson J, Welch V, Losos M, Tugwell P. The Newcastle-Ottawa Scale (NOS) for assessing the quality of nonrandomised studies in meta-analyses. Canada: Department of Epidemiology and Community Medicine UoO; 2000.

11. Higgins JP, Thompson SG. Quantifying heterogeneity in a meta-analysis. Stat Med. 2002;21(11):1539-58.

12. Egger M, Smith GD, Schneider M, Minder C. Bias in meta-analysis detected by a simple, graphical test. BMJ. 1997;315(7109):629-34.

13. Liberati A, Altman DG, Tetzlaff J, Mulrow C, Gotzsche PC, loannidis JP, Clarke M, Devereaux PJ, Kleijnen J, Moher D. The PRISMA statement for reporting systematic reviews and meta-analyses of studies that evaluate health care interventions: explanation and elaboration. PLoS Med. 2009;6(7):e1000100.

14. Wu Y-H, Liao Y-C, Chen Y-H, Chang M-H, Lin C-H. Risk of premotor symptoms in patients with newly diagnosed PD: a nationwide, populationbased, case-control study in Taiwan. PLoS One. 2014;10(6):e0130282.

15. Pont-Sunyer C, Hotter A, Gaig C, Seppi K, Compta Y, Katzenschlager R, Mas $N$, Hofeneder $D$, Brücke T, Bayés $A$, et al. The onset of nonmotor symptoms in parkinson's disease (the onset pd study). Mov Disord. 2015;30(2):229-37.

16. Baig F, Lawton M, Rolinski M, Ruffmann C, Nithi K, Evetts SG, Fernandes HR, Ben-Shlomo Y, Hu MT. Delineating nonmotor symptoms in early Parkinson's disease and first-degree relatives. Mov Disord. 2015;30(13):1759-66.

17. Trinh J, Amouri R, Duda JE, Morley JF, Read M, Donald A, Vilarino-Gueell C, Thompson C, Tu CS, Gustavsson EK, et al. A comparative study of Parkinson's disease and leucine-rich repeat kinase 2 p.G2019S parkinsonism. Neurobiol Aging. 2014;35(5):1125-31.

18. Khoo TK, Yarnall AJ, Duncan GW, Coleman S, O'Brien JT, Brooks DJ, Barker RA, Burn DJ. The spectrum of nonmotor symptoms in early Parkinson disease. Neurology. 2013;80(3):276-81.

19. Adler CH, Hentz JG, Shill HA, Sabbagh MN, Driver-Dunckley E, Evidente VG, Jacobson SA, Beach TG, Boeve B, Caviness JN. Probable RBD is increased in Parkinson's disease but not in essential tremor or restless legs syndrome. Parkinsonism Relat Disord. 2011;17(6):456-8. 
20. Chaudhuri KR, Martinez-Martin P, Schapira AH, Stocchi F, Sethi K, Odin P, Brown RG, Koller W, Barone P, MacPhee G, et al. International multicenter pilot study of the first comprehensive self-completed nonmotor symptoms questionnaire for Parkinson's disease: the NMSQuest study. Mov Disord. 2006;21(7):916-23.

21. Sixel-Doering F, Trautmann E, Mollenhauer B, Trenkwalder C. Rapid Eye movement sleep behavioral events: a new marker for neurodegeneration in early Parkinson disease? Sleep. 2014;37(3):431.

22. Howell MJ, Schenck $\mathrm{CH}$. Rapid eye movement sleep behavior disorder and neurodegenerative disease. JAMA Neurol. 2015;72(6):707-12.

23. Chen MC, Yu H, Huang Z-L, Lu J. Rapid eye movement sleep behavior disorder. Curr Opin Neurobiol. 2013;23(5):793-8.

24. Postuma RB, Gagnon JF, Vendette M, Montplaisir JY. Markers of neurodegeneration in idiopathic rapid eye movement sleep behaviour disorder and Parkinson's disease. Brain. 2009:132(Pt 12):3298-307.

25. Iranzo A, Tolosa E, Gelpi E, Molinuevo JL, Valldeoriola F, Serradell M, Sanchez-Valle R, Vilaseca I, Lomena F, Vilas D, et al. Neurodegenerative disease status and post-mortem pathology in idiopathic rapid-eyemovement sleep behaviour disorder: an observational cohort study. Lancet Neurol. 2013;12(5):443-53.

26. Postuma RB, Iranzo A, Hogl B, Arnulf I, Ferini-Strambi L, Manni R, Miyamoto T, Oertel W, Dauvilliers Y, Ju YE, et al. Risk factors for neurodegeneration in idiopathic rapid eye movement sleep behavior disorder: a multicenter study. Ann Neurol. 2015;77(5):830-9.

27. Schenck CH, Boeve BF, Mahowald MW. Delayed emergence of a parkinsonian disorder or dementia in $81 \%$ of older men initially diagnosed with idiopathic rapid eye movement sleep behavior disorder: a 16-year update on a previously reported series. Sleep Med. 2013;14(8):744-8.

28. Iranzo A, Lomena F, Stockner H, Valldeoriola F, Vilaseca I, Salamero M, Molinuevo JL, Serradell M, Duch J, Pavia J, et al. Decreased striatal dopamine transporter uptake and substantia nigra hyperechogenicity as risk markers of synucleinopathy in patients with idiopathic rapid-eye-movement sleep behaviour disorder: a prospective study [corrected]. Lancet Neurol. 2010;9(11):1070-7.

29. Fantini ML, Gagnon JF, Petit D, Rompre S, Decary A, Carrier J, Montplaisir J. Slowing of electroencephalogram in rapid eye movement sleep behavior disorder. Ann Neurol. 2003:53(6):774-80.

30. Fantini ML, Postuma RB, Montplaisir J, Ferini-Strambi L. Olfactory deficit in idiopathic rapid eye movements sleep behavior disorder. Brain Res Bull. 2006;70(4-6):386-90.

\section{Submit your next manuscript to BioMed Central and we will help you at every step:}

- We accept pre-submission inquiries

- Our selector tool helps you to find the most relevant journal

- We provide round the clock customer support

- Convenient online submission

- Thorough peer review

- Inclusion in PubMed and all major indexing services

- Maximum visibility for your research

Submit your manuscript at wuw biomedcentral.com/submit

) Biomed Central 